\title{
Hand of God in Psychosocial Rehabilitation
}

\author{
Santosh K. Chaturvedi
}

Received: 28 May 2018/Accepted: 28 May 2018/Published online: 31 May 2018

(C) Springer (India) Private Ltd., part of Springer Nature 2018

Religion is an important part of social, cultural and traditional life. It definitely has an impact on a person with a mental illness, like any other human being. Religion does not discriminate. In most management plans for rehabilitation, not much attention is given to religion and religious aspects. Religion influencing content of hallucinations and delusions is often encountered, as is religious psychopathology in dissociative disorders and both common and severe mental illnesses. However, the scope of religion goes beyond psychopathology and clinical diagnosis.

In many developing countries, including India, irrespective of religion, most persons with severe and chronic mentally illness live with their families. Further, families are involved in all aspects of care of the person, including personal hygiene, taking them for treatment, and deciding about their family life and rehabilitation. When psychiatric care involves hospitalization, a family member is needed to stay with the patient in many institutions, except institutions where patients are admitted involuntarily under the mental health act. Traditionally, elders of the family, invariably eldest male, have the final say in all important matters of the family in relation to treatment and rehabilitation. Religious traditions determine such

S. K. Chaturvedi $(\square)$

Psychiatric Rehabilitation Services, National Institute of Mental Health and Neurosciences, Bengaluru, India

e-mail: skchatur@gmail.com decisions. No wonder, psychiatrists are often faced with dilemmas to discuss care with the family heads, rather than with the patient. Religious leaders, somehow, supersede the family heads. It is important to understand this dynamics for planning appropriate care and rehabilitation of a person with mental illness. An interesting observation about role of families especially expressed emotions, are related to religious topics. Caregivers and relatives may insist on religious or traditional rituals, which may become a reason for critical comments, or over involvement, leading to interpersonal conflicts.

In certain families, religion may have a significant role while deciding treatment of psychiatric disorders. On one hand patients prefer medical treatments, like a medication tablet or a capsule. On the other hand they also expect a religious oriented psychological intervention. The pathways to care in patients with mental illness could come via the route through magico religious treatment or an intervention by a religious person or faith healer.

Religion at times can interfere with medical treatment, as some persons refuse to accept a tablet, capsule, liquid or injection on religious grounds. Same way, compliance to oral medications is a challenge when the person is on a religious fast. This could happen on any day, as there are fasts on different days to appease or pray different Gods! For example, people who pray to Lord Shiva keep a fast on mondays, and on fridays for Goddess Santoshi mata, 
and Saturday for Shani dev. Besides these days, fasts are also popular on a new moon day and full moon day, eleventh day [Ekadashi] of Hindu calendar and different festivals. Fasting during Ramadan, calls for altering the timing of medications to be taken, between sunset and sunrise! Another issue related to treatment which can potentially cause a religious conflict is whether the capsule coat/cover of the medication is made of vegetable matter or an animal product or gelatin!

Involuntary hospitalizations and quasi voluntary admissions are done within religious homes and centers. Persons with mental health problems are left alone or stay with the family member at the religious place till they recover from their mental health problem. Religious interventions like special diet, rituals, and prayers are used during these interventions. Many temples, dargahs and churches allow mentally ill person to stay in their premises, to take care of them, and also engage them in religious service or involve them in the activities of the religious place. In return the person gets food, shelter and security. Family feels reassured with this arrangement. Some religious organizations and places keep the mentally ill persons for a long period and even lifelong. Such 'Religious rehabilitation' centers exist in religious places known for their healing powers.

Religious coping is one of the commonest methods used for life stresses and mental health problems. Fatalism is one of the religious coping methods noted in clinical practice, and there are some indications that the strength of religious beliefs may provide wellbeing to the caregivers, and can become a part of family intervention programmes. Indian families believe in causes like supernatural forces, for mental health problems, and seek help from magico religious healers. Religious and magico religious interventions are popular and many times have been tried prior to seeking modern medical treatment. Off hand, it would be rather difficult to comment on their effectiveness; their popularity may be interpreted as their evidence for providing relief for those who seek these, or these might be popular, due to their low costs. At times, some such interventions can be very expensive!

Certain holy and religious towns and cities are known to provide mental peace and solace, especially for the elderly, widows, orphans and destitute, with or without mental health problems. The elderly or widows live in these towns in the precincts of temples or homes arranged by religious organizations, till the end of their life. There are other holy places where people visit periodically for blessings and prosperity or other wishes they want fulfilled. Spiritual care may not be an essential component of psychiatric care or rehabilitation professed by professionals, however, it is considered important by the family and the society, especially as medical resources are limited. Interestingly, religion has a positive stigma/discrimination as most religions encourage people to help those with deprivation and disease, including mental illness. Persons with intellectual and physical disabilities and severe mental illness are considered 'special or chosen ones by Gods' and hence serving them is a service to the religion.

There are many systems of alternate and unorthodox medicine, with some link with spirituality, for all religions. Complementary and alternative medicines play a key role in emotional support and improve the quality of life, to some extent, due to some overlap or admixture with faith and spirituality. The availability and relatively low cost of numerous systems of alternative medicine and a hope for cure means that many patients depend on these as their main form of treatment. These methods with unproven results, however, attract the gullible patients. It is difficult to balance and compare the perceived benefits of these Hindu practices and beliefs with those of modern psychiatric treatments. Likewise, it is difficult to estimate the perceived harm or disadvantage due to inability to practice the religious rituals, as compared to the harms (adverse drug reactions) of the medications. Patients continue to practice both systems, and the practitioners have to bank on their own wisdom and experience from such practice. Yoga, meditation and mindfulness, deep breathing exercises are some of the complementary methods which can become a part of the rehabilitation process.

At times, religious practices potentially interfere with the medical care, making it difficult for the mental health professionals to maintain adherence. Religious practices also emerge as a support for the individual and the family. The mental health professionals need to understand the cultural and religious backgrounds of their patients, to effectively provide care.

The Journal has entered into the fifth year, with increasing popularity and academic value. On one hand the number of submissions has increased from 
different parts of the world, on the other hand the journal is planning to increase the number of issues and pages to cope with the increased submissions. The current issue is unique by including submissions found suitable for publication from Canada, Greece, Hong Kong, Sweden, Poland, Ireland, Norway, USA and India. These include articles on the progress of clients with mood and anxiety disorders in a Day Hospital program: Examination of Clinical, Functional and Recovery Outcomes, Community Mental Health Providers' and Users' Perceptions on Dealing with the Crisis in Greece, Service Users Experience of Peer Support in Swedish Mental Health Care: A "Tipping Point" in the Care-Giving Culture? Along with this, there are a couple of articles on meaning of recovery for children and adolescents, and adults recovering from schizophrenia. Lastly, besides the Clubhouse
Staffs' Experiences of Working Side-by-side with Members, there are papers on burden and expressed emotions in caregivers of bipolar disorders and a theoretical enquiry on synergism of Adaptive Skills and Supports in Psychosocial Rehabilitation. The experiences from Poland on applying SCOPE to measure social inclusion among people with mental illness are another valuable publication in this issue.

Though none of the articles in this issue are actually related to religion and rehabilitation, the purpose of this editorial is to draw attention of mental health professionals and others interested or involved in recovery and rehabilitation to be sensitive to the religious aspects of a person's life. Religious activities can be encouraged for the person with mental health problem in the same way like advocating other social or occupational or educational activities. 